\title{
Family resemblances facilitate formation and expansion of functional equivalence classes in pigeons
}

\author{
MASAKO JITSUMORI, NAOKI SHIMADA, and SANA INOUE \\ Chiba University, Chiba, Japan
}

\begin{abstract}
Four pigeons were given repeated reversal training and testing with photographs of human faces constituting two categories structured by family resemblances, each consisting of a prototype, good exemplars, and poor exemplars. Each of the good exemplars (AM, BM, and CM) was created by 50\% morphing of the prototype (M) and one of the poor exemplars (A, B, and C, respectively) and thus was physically similar to the prototype and to the corresponding poor exemplar. The pigeons were first trained and tested for the formation of two (AM, BM, and CM) classes. Then, the stimulus sets were extended to include (1) M and the poor exemplars that were not physically similar to one another and (2) $50 \%$ morphs of the poor exemplars (AB, BC, and CA). In the sequentially introduced training and test phases, we successfully tracked expansion of the functional equivalence classes consisting of exemplars that had little similarity but could be linked together through other members of the class.
\end{abstract}

In one of its senses, concept refers to the behavioral phenomena by which diverse objects are grouped on the basis of a shared function. Whenever we label different objects with the same word (e.g., "chair"), they are regarded as functionally the same despite their differences in appearance. How can we demonstrate that nonhuman animals that respond to diverse objects in the same way actually treat them as functionally equivalent? Lea (1984) argued that if a change in responding to some stimuli of a set propagates to all remaining stimuli of that set without further training, and to a larger degree than can be accounted for by perceptual similarities among the stimuli, one can say that the set constitutes a functional equivalence class (see also Herrnstein, 1990; Kendler \& Kendler, 1968).

Vaughan (1988) was the first to demonstrate the formation of functional equivalence classes by pigeons. He presented pigeons with 40 slides of trees arbitrarily divided into two sets. In a go/no-go discrimination procedure, the contingencies of reinforcement for each stimulus set were repeatedly changed, whereas the functional differentiation of stimuli across classes remained intact. Such covarying functions in repeated reversal training enabled the pigeons to generalize the reversals to all the stimuli in each set

This research was supported by Grant 16530465 from the Japan Society for the Promotion of Science to the first author. A portion of this work was presented as an invited talk at the International Congress of Psychology, Beijing, August 2004. Special thanks to Juan D. Delius, without whose encouragement this study would not have been possible. We also thank Miyuki Ito, who carried out some of the phases of the experiments, and an anonymous reviewer for thoughtful comments and suggestions. Correspondence concerning this article should be addressed to M. Jitsumori, Department of Cognitive and Information Sciences, Faculty of Letters, Chiba University, L-33 Yayoi-Cho, Inage-Ku, Chiba 263-8522, Japan (e-mail: masako@cogsci.l.chiba-u.ac.jp). after they encountered reversed contingencies with just a few stimuli from the set, despite the fact that there was no reason to group or divide the stimuli on the basis of their physical similarities or dissimilarities. The result indicated that the pigeons had partitioned the stimuli into two subsets - that is, the discrimination reversals had generated two functional equivalence classes.

Since then, the formation of non-similarity-based functional classes has been examined through the use of physically unrelated visual stimuli, such as colors, tilted lines, and geometric shapes. With appropriate variations of the so-called symbolic matching procedure, it has been well documented that animals, specifically pigeons, can learn equivalence between sample stimuli that are associated with an identical comparison stimulus or with an identical response outcome (for reviews, see Roberts, 1996; Urcuioli, 1996; Zentall, 1996, 1998; see also Neiman \& Zentall, 2000). Pigeons have also been shown to learn equivalences among photographs of objects from different categories when the photographs are associated with a common response in a forced choice discrimination procedure (see, e.g., Astley \& Wasserman, 1998, 1999; Bhatt \& Wasserman, 1989; Bhatt, Wasserman, Reynolds, \& Knauss, 1988; Wasserman, De Volder, \& Coppage, 1992). These studies documented that pigeons are capable of learning equivalences among physically unrelated stimuli by virtue of their association with a common event, such as a common stimulus, a common response, or a common outcome (Zentall, Galizio, \& Critchfield, 2002).

More recently, Jitsumori, Siemann, Lehr, and Delius (2002), using a variation of the repeated reversal design used by Vaughan (1988; see also Delius, Ameling, Lea, \& Staddon, 1995, and Siemann \& Delius, 1998, in pigeons; Fersen \& Delius, 2000, in dolphins; and Sidman, Wynne, Maguire, \& Barnes, 1989, in brain-damaged humans), ex- 
amined whether pigeons are able to interrelate separately learned functional equivalences to yield the emergence of untrained equivalence. In a two-key forced choice discrimination procedure, they trained pigeons to discriminate dot matrix patterns arbitrarily divided into two sets, with the stimuli in one set designated A1, B1, C1, and D1 and those in the other set designated A2, B2, C2, and D2. Through a series of sequentially introduced repeated reversals, the pigeons were trained on $\mathrm{A} \leftrightarrow \mathrm{B}, \mathrm{B} \leftrightarrow \mathrm{C}, \mathrm{C} \leftrightarrow \mathrm{D}$, and $\mathrm{D} \leftrightarrow \mathrm{A}$ equivalences. To teach pigeons the $\mathrm{A} \leftrightarrow \mathrm{B}$ equivalence, for example, Jitsumori et al. first trained them with four pairs of the positive and negative stimuli: $\mathrm{A} 1+\mathrm{A} 2-$, $\mathrm{B} 1+\mathrm{B} 2-, \mathrm{A} 1+\mathrm{B} 2-$, and $\mathrm{B} 1+\mathrm{A} 2-$. The pigeons were then trained with the reversed $(\mathrm{A} 1-\mathrm{A} 2+, \mathrm{B} 1-\mathrm{B} 2+$, $\mathrm{A} 1-\mathrm{B} 2+$, and $\mathrm{B} 1-\mathrm{A} 2+)$ pairs, then again with the rereversed $(\mathrm{A} 1+\mathrm{A} 2-, \mathrm{B} 1+\mathrm{B} 2-, \mathrm{A} 1+\mathrm{B} 2-$, and $\mathrm{B} 1+\mathrm{A} 2-)$ pairs, and so on. The pigeons generally showed difficulty in learning the explicitly trained equivalences, and only 2 of 4 pigeons exhibited emergence of only one of two untrained equivalences. For example, $\mathrm{A} \leftrightarrow \mathrm{C}$ equivalence emerged transitively through the acquired $\mathrm{A} \leftrightarrow \mathrm{B}$ and $\mathrm{B} \leftrightarrow$ $\mathrm{C}$ equivalences. That is, the pigeons correctly chose $\mathrm{C} 1$ or $\mathrm{C} 2$ from the $\mathrm{C} 1 \mathrm{C} 2$ test pair according to the contingencies of reinforcement applied to the A1A2 training pair that were reversed between two successive test sessions (i.e., $\mathrm{A} 1+\mathrm{A} 2-$ in one session and $\mathrm{A} 1-\mathrm{A} 2+$ in the other). Similarly, the contingencies of reinforcement that were in effect for the $\mathrm{C} 1 \mathrm{C} 2$ training pair controlled the pigeons' choices of A1 or A2 when presented with the A1A2 test pairs on probe trials. No baseline set of trials ever included both $\mathrm{A}$ and $\mathrm{C}$, so these could not have become directly related as members of the same class. The only way the $\mathrm{A} \leftrightarrow \mathrm{C}$ relation could have come about was that $\mathrm{A}$ and $\mathrm{C}$ had been related to the same member (B) in each class (for a similar argument, see also Sidman, 1994, pp. 457-458). However, in other cases the pigeons generally tended to respond to test stimuli according to the contingencies that were applied when the test stimuli had last served as reinforced training stimuli. The very small number of dissimilar stimuli within the sets might have promoted idiosyncratic (within-session) learning rather than functional equivalence (across-session) learning during repeated reversal training.

In these studies, the experimenter-defined stimulus sets consisted of stimuli that bore no obvious physical similarity to one another. However, in natural settings, stimuli that share a function may sometimes be physically similar to one another. Empirical studies of natural categorization by human subjects (e.g., Rosch, 1978; Rosch \& Mervis, 1975) revealed that most natural categories consisting of highly variable members are internally structured by so-called family resemblances (Wittgenstein, 1953). For example, ostriches and penguins do not have attributes shared by many other birds and are not very similar to each other, but we place them into the same category due to the existence of many other kinds of birds. Such categorical coherence may be exploited by the visual systems of diverse animal species, including humans and pigeons, since it has been shown that pigeons trained to classify photographs depicting natural objects into true categories learn much faster than pigeons trained to sort the same photographs into pseudocategories (see, e.g., Herrnstein \& de Villiers, 1980; Wasserman, Kiedinger, \& Bhatt, 1988).

Resemblances among stimuli may guide not only categorization of the stimuli but also learning about functional equivalences among the highly variable category members. The simplest form of category that bears family resemblances consists of exemplars such as $\mathrm{AB}, \mathrm{BC}, \mathrm{CD}$, and DE. The centrally located, good exemplars (BC and $\mathrm{CD})$ possess only features that are shared by other exemplars. The peripherally located, poor exemplars (AB and $\mathrm{DE}$ ) do not share features, but the category as a whole is structured by family resemblances. Functional equivalences between perceptually similar exemplars $\mathrm{AB}$ and $\mathrm{BC}$ and between $\mathrm{BC}$ and $\mathrm{CD}$ may be learned with ease, which will possibly promote the emergence of untrained equivalence between the perceptually dissimilar exemplars $\mathrm{AB}$ and $\mathrm{CD}$ by means of their common equivalence to BC. Such an emergent relationship will be referred to as perceptual transitivity in this study, to differentiate it from the formal transitivity that occurs among perceptually unrelated stimuli in conditional discrimination (see, e.g., Sidman, 1994). Emergence of the untrained $A B \leftrightarrow C D$ equivalence may indicate that $\mathrm{AB}, \mathrm{BC}$, and $\mathrm{CD}$ have been learned as members of the same functional equivalence class. When the pigeon learns that a new stimulus DE is equivalent to the perceptually similar exemplar $\mathrm{CD}$, this relation may propagate to the other members of the class without direct training, thus forming a functional equivalence class consisted of $\mathrm{AB}, \mathrm{BC}, \mathrm{CD}$, and $\mathrm{DE}$.

We may speculate that the cognitive systems of diverse animal species are designed to take advantage of resemblances within categories. We have not found any studies, however, that explored the effects of such resemblances on the formation of functional equivalence classes in pigeons, although it has been repeatedly shown that pigeons successfully classify photographs of natural objects (see, e.g., Herrnstein, 1984; see also reviews in Jitsumori \& Delius, 2001, and Watanabe, Lea, \& Dittrich, 1993).

In the present study, we created visual categories structured according to family resemblances by means of morphing of human faces. Figure 1 shows examples of morphing of human faces. Unlike compound stimuli (such as a vertical line on a red field), facial properties and surface features of a morphed image are not exactly the same as the originals from which the image was created, and the morphed image changes gradually from one original to the other on a morph dimension. We used morphing to create categories based on the findings of Makino and Jitsumori (2000, Experiment 1). They trained pigeons to discriminate photographs of two positive human faces (one male and one female) from photographs of two negative human faces (one male and one female) in a go/no-go discrimination procedure. The pigeons were then tested with different series of photographs, produced through morphing, that ranged from one positive face to one negative face $(\mathrm{P}-\mathrm{N})$, from one positive face to the other positive face $(\mathrm{P}-\mathrm{P})$, and from one negative face to the other negative face 

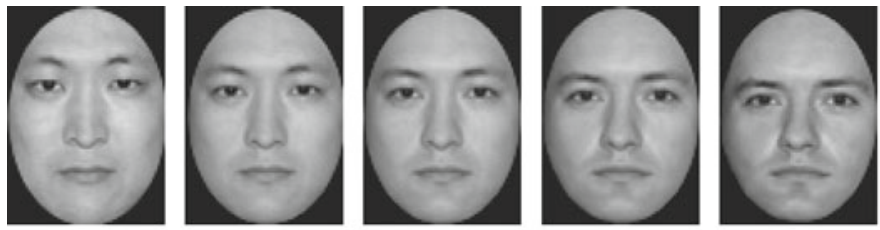

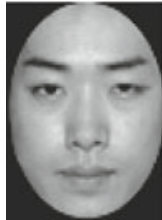

0

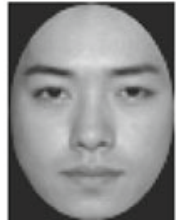

35

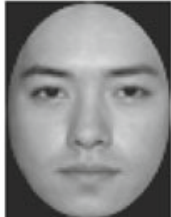

50

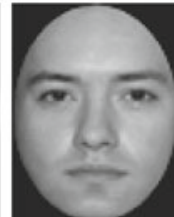

75

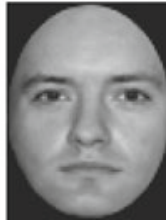

100

\section{Morph Percentage}

Figure 1. Examples of morphing of human faces. Morph percentage represents the percentage of the face on the far right.

$(\mathrm{N}-\mathrm{N})$. Generalization along the $\mathrm{P}-\mathrm{N}$ morph dimension was linearly related to the morph proportion of the positive face. Thus, a boundary stimulus on the face morph dimension-say $50 \% \mathrm{P} 50 \% \mathrm{~N}$ - is perceptually different from $\mathrm{P}$ and from $\mathrm{N}$. In contrast, generalization gradients along the $\mathrm{P}-\mathrm{P}$ and $\mathrm{N}-\mathrm{N}$ morph dimensions were virtually flat, with high rates of responding to all the $\mathrm{P}-\mathrm{P}$ morphs and low rates of responding to all the $\mathrm{N}-\mathrm{N}$ morphs. Thus, $50 \% \mathrm{P} 50 \% \mathrm{P}$ and $50 \% \mathrm{~N} 50 \% \mathrm{~N}$ are substantially similar to their respective originals. The findings suggested that a $50 \%$ average of two original faces is perceptually different from the originals but still substantially similar to both of them (see also Fields et al., 2002).

The categories used in this study consisted of a centrally located exemplar (M), peripherally located poor exemplars (A, B, and $\mathrm{C})$, their $50 \%$ morphs $(50 \% \mathrm{~A} 50 \% \mathrm{~B}$, $50 \% \mathrm{~B} 50 \% \mathrm{C}$, and $50 \% \mathrm{C} 50 \% \mathrm{~A})$, and good exemplars created by morphing $\mathrm{M}$ and each of the poor exemplars (50\%A $50 \% \mathrm{M}, 50 \% \mathrm{~B} 50 \% \mathrm{M}$, and 50\%C50\%M). An advantage of this category system is that it is possible to create open-ended categories consisting of a large number of exemplars. We used $50 \%$ morphing only, so we will represent the morphed stimuli simply by their originals in the following sections. For example, $50 \% \mathrm{~A} 50 \% \mathrm{M}$ will be referred to as "AM." Figure 2 shows black-and-white reproductions of the stimuli used in the present study. Within each set, the good exemplars (AM, BM, and CM) were substantially similar to $\mathrm{M}$ and also to the corresponding poor exemplars, and they were similar to one another but potentially discriminable. In this way, the category was designed to be structured by family resemblances.

In the first stage of class formation training, we trained and tested pigeons for the formation of (AM, BM, CM) perceptual classes (Experiment 1). The stimulus classes were then extended to include $\mathrm{M}$ and the poor exemplars (A, B, and $C$ ) that were not particularly similar to one another (Experiments 2 and 3 ) and 50\% morphs of the poor exemplars (AB, BC, and CA, Experiments 4 and 5). The goal of repeated reversal training and testing was to determine whether pigeons are able to integrate separately learned functional equivalences and to establish an equivalence network consisting of various exemplars that are internally related to one another through family resemblances.

\section{EXPERIMENT 1}

Experiment 1 established perceptual classes consisting of the good exemplars-AM1, BM1, and CM1 in Set 1 and $\mathrm{AM} 2, \mathrm{BM} 2$, and CM2 in Set 2. In a repeated reversal format similar to that used by Jitsumori et al. (2002), we trained $\mathrm{AM} \leftrightarrow \mathrm{BM}$ and then $\mathrm{BM} \leftrightarrow \mathrm{CM}$ repeated reversals. Following training, the formation of the untrained $\mathrm{AM} \leftrightarrow \mathrm{CM}$ relation was tested. The test for the $\mathrm{AM} \leftrightarrow \mathrm{CM}$ relation consisted of an $\mathrm{AM} \rightarrow \mathrm{CM}$ test and a $\mathrm{CM} \rightarrow \mathrm{AM}$ test, between which the training and test roles of the stimuli were exchanged symmetrically. For the $\mathrm{AM} \rightarrow \mathrm{CM}$ test, for example, the training and test pairs were AM1AM2 and CM1CM2, respectively. The reinforcement allocation of the training pair was reversed between two successive test sessions. The choice of CM1 was scored as correct in the test session in which AM1 + and AM2- were used in training trials, whereas the choice of CM2 was scored as correct in the test session in which AM1 - and AM2 + were used in training trials. Because the good exemplars within the sets were physically similar to one another, correct choices of test stimuli could be due to spontaneous perceptual generalization between the training and test pairs that appeared in the same test session. A question of interest was whether the pigeons would switch their choices on test trials according to the contingencies of reinforcement that were in effect on training trials, or respond on the basis of the contingencies that were applied when the test pair had last served as a reinforced training pair. If the pigeons correctly switch their choices on test trials in both the $\mathrm{AM} \rightarrow \mathrm{CM}$ and $\mathrm{CM} \rightarrow \mathrm{AM}$ tests, it suggests that they learned the (AM, BM, CM) classes on the basis of 

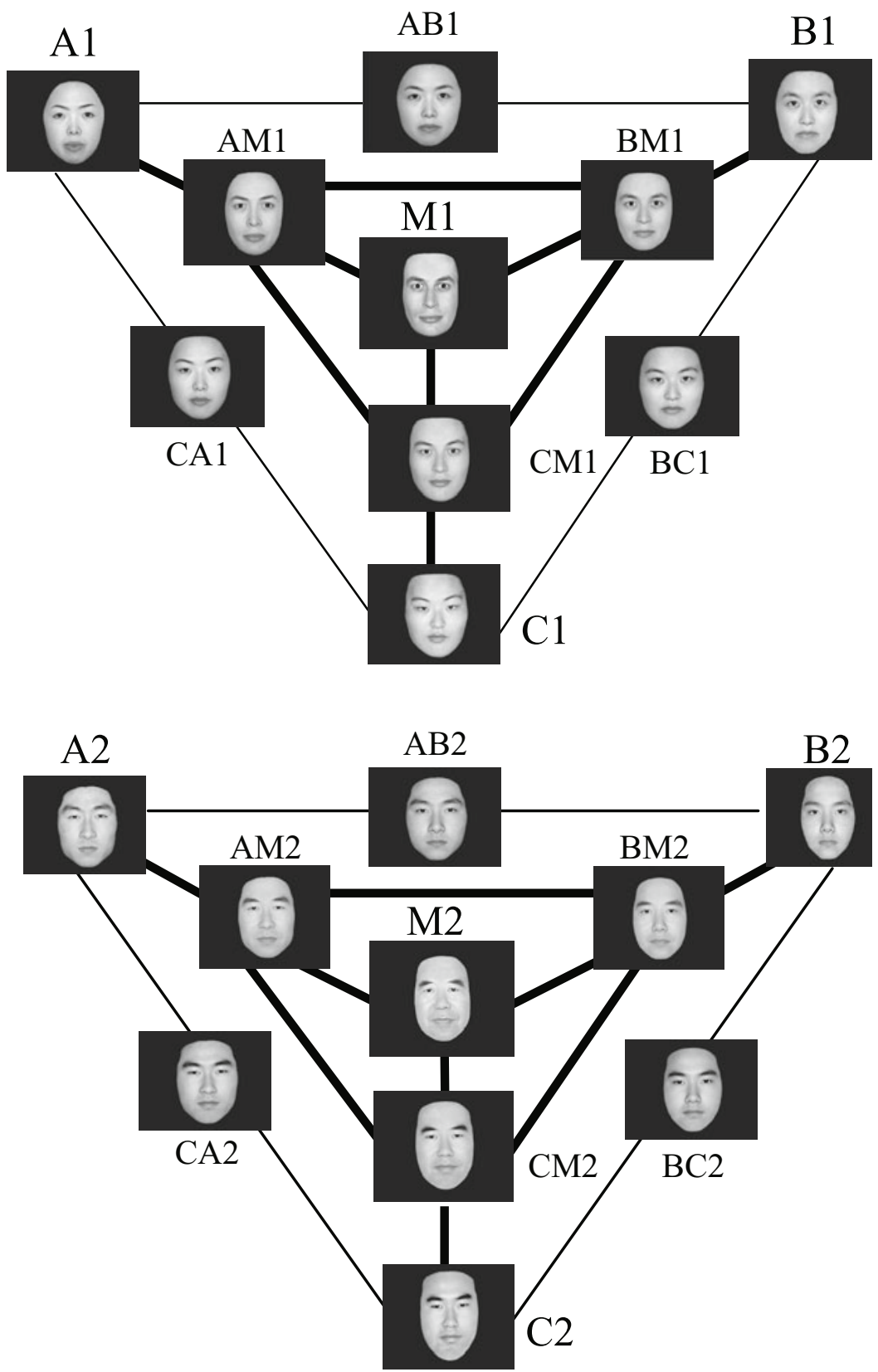

Figure 2. Black-and-white reproductions of the face stimuli in Set 1 (top) and Set 2 (bottom). The $50 \%$ morphed images are labeled according to the originals from which they were created.

perceptual similarities, covarying function, or both (see also Delius, Jitsumori, \& Siemann, 2000). If, on the other hand, the pigeons respond to test stimuli according to the most recently valid contingencies of reinforcement, we have to conclude that they failed to form the (AM, BM, $\mathrm{CM})$ classes.

\section{Method}

\section{Subjects}

Four experimentally naive homing pigeons (Columba livia) of local stock were maintained at $90 \%$ of their free-feeding weights.
They were housed in individual cages $(40 \times 40 \times 45 \mathrm{~cm})$. Water was freely available. Grit was freely available except during the experimental sessions.

\section{Apparatus}

During experimental sessions, conditioning platforms were attached to the outside of each pigeon's home cage (see Xia, Delius, \& Siemann, 1996, for details). Each pigeon had access to its own platform, which contained two clear response keys $(3 \times 3 \mathrm{~cm})$ that could be reached through a cage opening through which the pigeons normally ate. The keys were located side by side. The centers of the keys were $4 \mathrm{~cm}$ apart. Directly under the keys was a TFT color moni- 
tor (Casio, EV-400). Dispensers affixed to the panel could deliver food reward (3-6 grains of millet) onto each key. A microcomputer system (DEC, PC-5000) controlled the experimental events and collected data.

\section{Stimuli}

Frontal photographs of eight human faces with neutral expressions were taken in color with a digital camera (Victor, GR-DVM1), all under the same lighting condition. The hair of the heads and ears was digitally removed, and the background was painted black using Photoshop (Adobe). Two stimulus sets were created using commercially available morphing software (Gryphon Morph). In Set 1, the centrally located stimulus (M1) was a photograph of a Danish male student. The peripherally located stimuli (A1, B1, and C1) were photographs of Japanese female students. The blue eyes of M1 were digitally changed to dark brown, similar to the eye color of the others. Good exemplars (AM1, BM1, and CM1) were created by means of $50 \%$ morphing of M1 and each of the poor exemplars. Similarly, Set 2 was created with a Japanese male professor as M2, Japanese male students as poor exemplars (A2, B2, and C2), and their 50\% morphs as good exemplars (AM2, BM2, and CM2). We used all female and all male pictures as the poor exemplars of Sets 1 and 2 , respectively, in an attempt to increase family resemblances within each set. The allocation of the faces to the stimuli designated A, B and $\mathrm{C}$ in each set was balanced as closely as possible across pigeons. Because the centrally located stimulus (M1 in Set 1 and M2 in Set 2) was physically similar to all the good exemplars, it was referred to as the prototype of the set. It may be worth noting that, in a more recent study (Jitsumori, 2006), pigeons showed a prototype effect with face morph categories created in the same way as in the present study. The pigeons were trained, in a go/no-go discrimination, to classify good exemplars of the positive and negative categories and were then tested for transfer to novel stimuli, each of which was created by morphing of the positive or negative prototype and one of the novel faces. Generalization along a series of photographs that ranged from a photograph of the novel face to the positive prototype increased as a function of face morph proportion of the positive prototype, with a peak of the positive generalization gradient at the prototype.

\section{Procedure}

The pigeons were trained to peck the keys with an autoshaping procedure (Brown \& Jenkins, 1968). A yellow circle (not illustrated and not used subsequently) was employed as the stimulus. Within a block of 40 trials, the stimulus appeared equally often under the left key and under the right key. As soon as the pigeons pecked the keys regularly, the training started.

$\mathbf{A M} \leftrightarrow \mathbf{B M}$ training. With the stimulus pairs $\mathrm{AM} 1+\mathrm{AM} 2-$, $\mathrm{BM} 1+\mathrm{BM} 2-, \mathrm{AM} 1+\mathrm{BM} 2-$, and $\mathrm{BM} 1+\mathrm{AM} 2-$, the pigeons were trained to choose AM1 or BM1 in Set 1 over AM2 or BM2 in Set 2. Each trial began with the presentation of each member of one of the stimulus pairs under one of the two keys. The presentation order of the eight stimulus configurations (including controls for position) was randomized within each of the eight-trial series in a block of 80 trials, with the restriction that the positive stimuli could not appear on the same key more than three times in succession within or across consecutive series. Three consecutive pecks on either one of the keys turned off the stimuli. Choice of the positive stimulus initiated a 2-sec reward period, with millet grains delivered to the corresponding dark key. Choice of the negative stimulus produced a 2 -sec time-out, during which the keys were illuminated red. After a 3 -sec intertrial interval, the next trial began. Following an incorrect choice, the same trial was repeated an unlimited number of times until the pigeon responded correctly. These correction trials were not taken into account for trial counts and performance scores.

A session consisted of one or more blocks of 80 trials and continued until the pigeon achieved $80 \%$ correct or better in a single block. If the pigeon did not reach the $80 \%$ criterion within $2 \mathrm{~h}$, its daily session was terminated. The training continued until the pi- geon reached this criterion in two successive sessions; in addition, the mean accuracy over the entire second session had to be at or above $80 \%$. Thus, the pigeon had to complete at least two training sessions before reaching this double criterion. On the following day, contingencies of reinforcement were reversed $(\mathrm{AM} 1-\mathrm{AM} 2+$, $\mathrm{BM} 1-\mathrm{BM} 2+, \mathrm{AM} 1-\mathrm{BM} 2+$, and $\mathrm{BM} 1-\mathrm{AM} 2+)$. Performance during the first few trials immediately after reversal was expected to be close to $0 \%$ correct, and training under this new condition continued until the pigeons again reached the criterion described above. The contingencies of reinforcement were then reversed again, and so on. Reversals were repeated until $80 \%$ or more correct responses were obtained during the first blocks following each of three successive reversals.

$\mathbf{B M} \leftrightarrow \mathbf{C M}$ training. The pigeons were then given $\mathrm{BM} \leftrightarrow \mathrm{CM}$ training. Procedural details were as in the previous training phase except that the stimuli were now BM1, BM2, CM1, and CM2.

Maintenance training. Following $\mathrm{BM} \leftrightarrow \mathrm{CM}$ training, the pigeons were given 16 additional training sessions. These were arranged in sets of either two $\mathrm{AM} \leftrightarrow \mathrm{BM}$ training sessions with opposite contingencies followed by two $\mathrm{BM} \leftrightarrow \mathrm{CM}$ training sessions with opposite contingencies, or vice versa. The order in which the pigeons were trained on these four 4-session sets was randomly determined. As in the previous training phases, a session terminated when the pigeons made $80 \%$ or more correct choices in a block of 80 trials.

$\mathbf{A M} \leftrightarrow \mathbf{C M}$ test. Testing sessions were designed to test the formation of untrained $\mathrm{AM} \leftrightarrow \mathrm{CM}$ relation. Probe trials were inserted among training trials to determine whether or not the contingencies of reinforcement that were used for training stimuli would control the pigeons' choice of test stimuli when they were included within the same session. Therefore, although no feedback was given on probe trials, the choices were scored as correct or incorrect according to the contingencies that were in effect for the training stimuli.

The test for $\mathrm{AM} \leftrightarrow \mathrm{CM}$ relation consisted of the $\mathrm{AM} \rightarrow \mathrm{CM}$ and $\mathrm{CM} \rightarrow \mathrm{AM}$ tests, between which the training and test roles of the stimulus pairs were exchanged symmetrically. For the $\mathrm{AM} \rightarrow \mathrm{CM}$ test, for example, the training and probe pairs were AM1AM2 and CM1CM2, respectively. The reinforcement allocation of the training pair was reversed between two successive test sessions. A total of four test sessions - two successive sessions for each of the $\mathrm{AM} \rightarrow \mathrm{CM}$ and $\mathrm{CM} \rightarrow \mathrm{AM}$ tests - took place. The test order was balanced across pigeons.

Each test session began with a block of 80 training trials and continued until the $80 \%$ correct criterion was reached within a block. This was immediately followed by a test block, which consisted of 60 training trials and 20 randomly inserted probe trials (10 repeats of 2 different probe trials, including control for left vs. right position). On probe trials, choice responses were not reinforced but led directly to an intertrial interval. In each of the $\mathrm{AM} \rightarrow \mathrm{CM}$ and $\mathrm{CM} \rightarrow \mathrm{AM}$ tests, the mean test performance over two successive test sessions was obtained, between which the contingencies of reinforcement for training stimuli were reversed. If the pigeons chose the test stimuli according to the contingencies that were most recently valid in the session in which these stimuli appeared as training stimuli, then the test performance would be nearly $100 \%$ correct in one testing session and nearly $0 \%$ correct in the other. Thus, the mean test performance over the two testing sessions would be about $50 \%$ correct. If they chose the test stimuli by chance, it would also be about $50 \%$ correct. Alternatively, it would be near $100 \%$ correct if they responded to the test stimuli according to the contingencies that were in effect for the training stimuli in each testing session. If the mean accuracies in the $\mathrm{AM} \rightarrow \mathrm{CM}$ and $\mathrm{CM} \rightarrow \mathrm{AM}$ tests were both statistically above chance, we considered $\mathrm{AM} \leftrightarrow \mathrm{CM}$ to be satisfied.

\section{Results and Discussion}

\section{Acquisition}

Birds 1, 3, and 4 completed AM $\leftrightarrow$ BM training after 27, 78 , and 47 reversals. Bird 2 continued to perform poorly 
immediately after the contingencies were reversed. This pigeon was dropped from the experiment after 80 reversals. Only Birds 1,3 , and 4 proceeded to $\mathrm{BM} \leftrightarrow \mathrm{CM}$ training. They all failed to reach the $80 \%$ correct criterion immediately after the first reversal in their $\mathrm{BM} \leftrightarrow \mathrm{CM}$ training, but Birds 1 and 4 quickly learned to switch their choices after reversals. Bird 3 required numerous reversals but completed $\mathrm{BM} \leftrightarrow \mathrm{CM}$ training more rapidly than it had the previous $\mathrm{AM} \leftrightarrow \mathrm{BM}$ training. Birds 1, 3, and 4 required 3,33 , and 4 reversals, respectively.

\section{Testing}

Table 1 shows the percent correct scores on probe trials for each of Birds 1, 3, and 4 during the $\mathrm{AM} \rightarrow \mathrm{CM}$ and $\mathrm{CM} \rightarrow \mathrm{AM}$ tests. All 3 pigeons showed $75 \%$ correct or better performance on probe trials in two successive test sessions between which the reinforcement allocation of training pair was reversed $(1+$ and $2+$ in the table). We evaluated the mean test performance scores for each test in terms of whether the binomial distribution score is significantly $(p<.05)$ above chance $(50 \%)$. The mean test performances significantly better than chance are shown in boldface. For each pigeon, the mean choice accuracy was significantly better than chance on both the $\mathrm{AM} \rightarrow \mathrm{CM}$ and $\mathrm{CM} \rightarrow \mathrm{AM}$ tests. The correct scores averaged among the pigeons were $91 \%$ in the $\mathrm{AM} \rightarrow \mathrm{CM}$ test and $90 \%$ in the $\mathrm{CM} \rightarrow \mathrm{AM}$ test.

The pigeons chose the test stimuli according to the contingencies that were in effect on training trials rather than according to those most recently applied to the probe pairs when they had appeared as reinforced training pairs. As such, any of the good exemplars contributed to causing the pigeons to switch their choices to all other good exemplars. We may thus consider that the pigeons established (AM, BM, CM) classes. However, as we noted earlier, the highly accurate probe performances shown by the pigeons could be explained by the occurrence of primary stimulus generalization within each test session.

\section{EXPERIMENT 2}

Experiment 2 was designed to examine whether or not the pigeons that had served as subjects in Experiment 1 would show the emergence of untrained equivalence be-

Table 1

Percent Correct Responses to Probe Pairs on the AM $\leftrightarrow$ CM ' 'est in Experiment 1

\begin{tabular}{lrrrrrrr}
\hline & \multicolumn{3}{c}{$\mathrm{AM} \rightarrow \mathrm{CM}$} & & \multicolumn{3}{c}{$\mathrm{CM} \rightarrow \mathrm{AM}$} \\
\cline { 2 - 4 } \cline { 6 - 8 } Subject & $1+$ & $2+$ & $M$ & & $1+$ & $2+$ & $M$ \\
\hline Bird 1 & 90 & 90 & $\mathbf{9 0}$ & 75 & 90 & $\mathbf{8 3}$ \\
Bird 3 & 100 & 75 & $\mathbf{8 8}$ & & 100 & 95 & $\mathbf{9 8}$ \\
Bird 4 & 100 & 90 & $\mathbf{9 5}$ & & 80 & 95 & $\mathbf{8 8}$ \\
Mean & 97 & 85 & $\mathbf{9 1}$ & & 85 & 93 & $\mathbf{9 0}$ \\
\hline
\end{tabular}

Note- $1+$ indicates that Set 1 is positive and Set 2 is negative on training trials. $2+$ indicates that Set 1 is negative and Set 2 is positive on training trials. Mean test performances significantly better than chance $(p<.05)$ are shown in boldface. tween the poor exemplars (A, B, and C) and the prototype (M), which were not particularly similar to one another. We trained the pigeons in $(\mathrm{A}, \mathrm{B}, \mathrm{C}) \leftrightarrow(\mathrm{AM}, \mathrm{BM}, \mathrm{CM})$ and $(\mathrm{AM}, \mathrm{BM}, \mathrm{CM}) \leftrightarrow \mathrm{M}$ equivalences and then examined whether the untrained $(\mathrm{A}, \mathrm{B}, \mathrm{C}) \leftrightarrow \mathrm{M}$ equivalence would emerge from the separately trained multiple equivalences. To evaluate the effects of $(\mathrm{A}, \mathrm{B}, \mathrm{C}) \leftrightarrow(\mathrm{AM}, \mathrm{BM}, \mathrm{CM})$ and $(\mathrm{AM}, \mathrm{BM}, \mathrm{CM}) \leftrightarrow \mathrm{M}$ training on the emergence of untrained $(\mathrm{A}, \mathrm{B}, \mathrm{C}) \leftrightarrow \mathrm{M}$ equivalence, we used an $\mathrm{A}-\mathrm{B}-\mathrm{A}$ design. That is, the $(A, B, C) \leftrightarrow M$ test was conducted twice, once before and once after the training.

To determine whether and to what extent the pigeons' test performances were based on similarity-based generalization, 2 experimentally naive pigeons were trained to discriminate the prototypes and then tested for transfer to the poor exemplars without any specific equivalence training. Two other experimentally naive pigeons were trained to discriminate the poor exemplars and then tested for transfer to the prototypes. Before the discrimination training and generalization testing were conducted, all the control group pigeons were given discrimination training with the good exemplars. This training phase was introduced because the experimental group pigeons had experienced the good exemplars in the previous experiment. For the control group pigeons, contingencies of reinforcement were never reversed across training sessions.

\section{Method}

\section{Subjects}

The 3 pigeons tested in Experiment 1 (Birds 1, 3, and 4) served as the experimental group. Four experimentally naive pigeons (Birds 5 , 6,7 , and 8) served as the control group. All the pigeons were maintained under the same conditions as in Experiment 1.

\section{Stimuli and Apparatus}

The stimuli and apparatus were the same as in Experiment 1.

\section{Experimental Group Procedure}

(AM, BM, CM) equivalence training. The pigeons tested in Experiment 1 (Birds 1, 3, and 4) were given equivalence training with all possible pairs of the good exemplars: AM1AM2, AM1BM2, AM1CM2, BM1AM2, BM1BM2, BM1CM2, CM1AM2, CM1BM2, and CM1CM2. Note that AM1CM2 and CM1AM2 had not previously been presented in pairs during Experiment 1. A session consisted of one or more blocks of 90 trials (five repeats of 18 stimulus configurations, including controls for position). Training continued until $80 \%$ or more correct responses were obtained during the first blocks following each of two successive reversals.

(A, B, C) $\leftrightarrow$ M Test 1. After the completion of (AM, BM, CM) equivalence training, the emergence of equivalence between the poor exemplars and the prototype was tested. For the (A, B, C) $\rightarrow$ M test, the training pairs were $\mathrm{A} 1 \mathrm{~A} 2, \mathrm{~A} 1 \mathrm{~B} 2, \mathrm{~A} 1 \mathrm{C} 2, \mathrm{~B} 1 \mathrm{~A} 2, \mathrm{~B} 1 \mathrm{~B} 2, \mathrm{~B} 1 \mathrm{C} 2$, $\mathrm{C} 1 \mathrm{~A} 2, \mathrm{C} 1 \mathrm{~B} 2$, and $\mathrm{C} 1 \mathrm{C} 2$. The probe pair was M1M2. Each test session began with one or more blocks of 72 training trials (four repeats of 18 stimulus configurations, including controls for position). Immediately after the $80 \%$ correct criterion was reached in a block, a test block consisting of 54 training trials and 18 randomly inserted probe trials was given. On the following day, the reinforcement allocation of the training pair was reversed. The reversal training continued until the pigeons regained the $80 \%$ correct criterion in a block. Then, a test block was given under the reversed condition. Four test sessions were given, with the contingencies of reinforcement being reversed between two successive test sessions. For the $\mathrm{M} \rightarrow(\mathrm{A}, \mathrm{B}, \mathrm{C})$ 
test, the training pair was M1M2 and probe pairs were $\mathrm{A} 1 \mathrm{~A} 2, \mathrm{~A} 1 \mathrm{~B} 2$, $\mathrm{A} 1 \mathrm{C} 2, \mathrm{~B} 1 \mathrm{~A} 2, \mathrm{~B} 1 \mathrm{~B} 2, \mathrm{~B} 1 \mathrm{C} 2, \mathrm{C} 1 \mathrm{~A} 2, \mathrm{C} 1 \mathrm{~B} 2$, and $\mathrm{C} 1 \mathrm{C} 2$. A total of 18 stimulus configurations (including controls for position) were tested once in a session. Other procedural details were as in the $(\mathrm{A}, \mathrm{B}, \mathrm{C}) \rightarrow \mathrm{M}$ test. Birds 1 and 3 received the $(\mathrm{A}, \mathrm{B}, \mathrm{C}) \rightarrow \mathrm{M}$ test first and then the $\mathrm{M} \rightarrow(\mathrm{A}, \mathrm{B}, \mathrm{C})$ test. The testing order was reversed for Bird 4. A total of 8 test sessions were given. Only pigeons who failed to show emergence of the (A, B, C) $\leftrightarrow \mathrm{M}$ equivalence proceeded to the following training and testing stages.

(A, B, C)↔(AM, BM, CM) training. A series of reversals was given to establish equivalence between the poor exemplars and the good exemplars. All possible stimulus pairs (including controls for position) appeared once in a block of 72 trials. A training session terminated after the pigeon reached the $80 \%$ correct criterion ( 58 or more correct choices) in a single block. On the following day, the reinforcement allocation of the training pair was reversed. Reversals were repeated until the pigeons reached the reversal criterion described above.

(AM, BM, CM) $\leftrightarrow$ M training. A series of reversals was then given to establish equivalence between the good exemplars and the prototype. All possible stimulus pairs (including controls for position) appeared twice in a block of 64 trials. A training session terminated after the pigeon reached the $80 \%$ correct criterion ( 52 or more correct choices) in a single block. Reversals were repeated until the pigeons reached the reversal criterion described above.

Maintenance training. Following the ( $\mathrm{AM}, \mathrm{BM}, \mathrm{CM} \leftrightarrow \mathrm{M})$ training, the pigeons were given 16 additional training sessions. Similar to the maintenance training in Experiment 1, these sessions were arranged in sets of either two $(\mathrm{A}, \mathrm{B}, \mathrm{C}) \leftrightarrow(\mathrm{AM}, \mathrm{BM}$, $\mathrm{CM}$ ) training sessions with opposite contingencies followed by two (AM, BM, CM) $\leftrightarrow \mathrm{M}$ training sessions with opposite contingencies, or vice versa.

$(\mathbf{A}, \mathbf{B}, \mathbf{C}) \leftrightarrow \mathbf{M}$ Test 2 . After the completion of $(\mathrm{A}, \mathrm{B}, \mathrm{C}) \leftrightarrow(\mathrm{AM}$, $\mathrm{BM}, \mathrm{CM})$ and $(\mathrm{AM}, \mathrm{BM}, \mathrm{CM}) \leftrightarrow \mathrm{M}$ training, the pigeons were again given the $(A, B, C) \leftrightarrow M$ test. Procedural details were as in (A, B, $\mathrm{C}) \leftrightarrow \mathrm{M}$ Test 1 .

\section{Control Group Procedure}

(AM, BM, CM) discrimination training. As soon as the control group pigeons had learned to peck the keys consistently, they received discrimination training with the good exemplars (AM, BM, and $\mathrm{CM}$ ) of Sets 1 and 2. Procedural details were as in the (AM, $\mathrm{BM}, \mathrm{CM}$ ) equivalence training given to the experimental group at the beginning of Experiment 2, except that the contingencies of reinforcement were never reversed. For Birds 5 and 7, the good exemplars in Set 1 were positive and those in Set 2 were negative, and the opposite was true for Birds 6 and 8. A training session terminated after the pigeon reached the $80 \%$ correct criterion in a single block of 90 trials. Training continued for at least 14 sessions and until performance during the first block was $80 \%$ correct or better in two consecutive daily sessions.

$(\mathbf{A}, \mathbf{B}, \mathbf{C}) \rightarrow \mathbf{M}$ transfer test. After the completion of (AM, BM, $\mathrm{CM}$ ) discrimination training, Birds 5 and 6 received discrimination training with the poor exemplars (A, B, and C) of Sets 1 and 2. The positive and negative roles of the stimuli for each pigeon were as in the previous (AM, BM, CM) discrimination training. A total of 18 stimulus configurations (including controls for position) appeared four times in a block of 72 trials. A training session terminated after the pigeon reached the $80 \%$ correct criterion in a single block. Training continued until performance during the first block was $80 \%$ correct or better in three consecutive sessions. The pigeons were then tested for transfer to the prototypes. Procedural details were as in the experimental group's $(A, B, C) \rightarrow M$ test, except that the contingencies of reinforcement on training trials were never reversed. Four test sessions were given.

$\mathbf{M} \rightarrow \mathbf{( A , ~ B , ~ C ) ~ t r a n s f e r ~ t e s t . ~ B i r d s ~} 7$ and 8 received discrimination training with the prototypes. The positive and negative roles of the stimuli for each pigeon were as in the previous (AM, BM, CM) discrimination training. Training continued until performance during the first block of 72 trials was at $80 \%$ or better in three consecutive sessions. The pigeons were then tested for transfer to the poor exemplars. Procedural details were as in the experimental group's $\mathrm{M} \rightarrow(\mathrm{A}, \mathrm{B}, \mathrm{C})$ test, except that the contingencies of reinforcement were never reversed. Four test sessions were given.

\section{Results}

\section{Experimental Group}

Birds 1,3 , and 4 completed the (AM, BM, CM) equivalence training after three, two, and three reversals, respectively. The pigeons then received $(\mathrm{A}, \mathrm{B}, \mathrm{C}) \leftrightarrow \mathrm{M}$ Test 1 . When contingencies of reinforcement on training trials were reversed during the $\mathrm{M} \rightarrow(\mathrm{A}, \mathrm{B}, \mathrm{C})$ test, none of the pigeons showed any difficulty in reversing their responses to the M1M2 training pair. During the $(\mathrm{A}, \mathrm{B}, \mathrm{C}) \rightarrow \mathrm{M}$ test, on the other hand, all the pigeons except for Bird 3 required numerous training blocks before a test block was administered in the reversed condition. For example, on the first reversal Birds 1 and 4 required 22 and 12 training blocks, respectively, to reach the $80 \%$ correct criterion. Only Bird 3 quickly reversed responses to the poor exemplar pairs in the first training block.

The left columns of Table 2 represent performance on probe trials during (A, B, C) $\leftrightarrow \mathrm{M}$ Test 1 . Surprisingly, 1 of the 3 pigeons (Bird 3 ) fully passed the tests. Bird 1 passed only the $\mathrm{M} \rightarrow(\mathrm{A}, \mathrm{B}, \mathrm{C})$ test. These findings will be discussed later. Bird 4 performed at about chance in both tests. Only Birds 1 and 4 received $(\mathrm{A}, \mathrm{B}, \mathrm{C}) \leftrightarrow(\mathrm{AM}, \mathrm{BM}, \mathrm{CM})$ and (AM, BM, CM) $\leftrightarrow \mathrm{M}$ training. Birds 1 and 4 completed the $(\mathrm{A}, \mathrm{B}, \mathrm{C}) \leftrightarrow(\mathrm{AM}, \mathrm{BM}, \mathrm{CM})$ training after 4 and 5 reversals and the (AM, BM, CM) $\leftrightarrow$ M training after 4 and 13 reversals, respectively. After 16 additional maintenance training sessions, they were given $(\mathrm{A}, \mathrm{B}, \mathrm{C}) \leftrightarrow \mathrm{M}$ Test 2 .

The right columns of Table 2 represent performance during $(\mathrm{A}, \mathrm{B}, \mathrm{C}) \leftrightarrow \mathrm{M}$ Test 2 . The pigeons fully passed the tests; thus, the untrained $(\mathrm{A}, \mathrm{B}, \mathrm{C}) \leftrightarrow \mathrm{M}$ equivalence emerged. Note also that, in each of the $(\mathrm{A}, \mathrm{B}, \mathrm{C}) \rightarrow \mathrm{M}$ and $\mathrm{M} \rightarrow(\mathrm{A}, \mathrm{B}, \mathrm{C})$ tests, the pigeons showed $70 \%$ or more correct responses on probe trials in both types of the $1+$ and $2+$ test sessions. The pigeons successfully changed their responses to test stimuli when contingencies of reinforcement for training stimuli were reversed.

\section{Control Group}

All the control group pigeons were first trained to discriminate among the good exemplars of the categories (AM1, BM1, and CM1 vs. AM2, BM2, and CM2), using all possible pairs of the stimuli that were presented during the (AM, BM, CM) training given to the experimental group pigeons at the beginning of Experiment 2. Note again that the contingencies of reinforcement were never reversed for the control group pigeons. They showed rapid acquisition and reached criterion within 14 sessions.

Birds 5 and 6 proceeded to discrimination training with the poor exemplars (A1, B1, and $\mathrm{C} 1$ vs. $\mathrm{A} 2, \mathrm{~B} 2$, and $\mathrm{C} 2$ ). Choice accuracy in the first 72-trial block was $57 \%$ for Bird 5 and $61 \%$ for Bird 6 . Percent correct choices improved rapidly; Birds 5 and 6 required a total of 14 and 
Table 2

Percent Correct Responses to Probe Pairs on the (A, B, C) $\leftrightarrow$ M ' 'ests in Experiment 2

\begin{tabular}{|c|c|c|c|c|c|c|c|c|c|c|c|c|}
\hline \multirow[b]{3}{*}{ Subject } & \multicolumn{6}{|c|}{$(\mathrm{A}, \mathrm{B}, \mathrm{C}) \leftrightarrow \mathrm{M}$ Test 1} & \multicolumn{6}{|c|}{$(\mathrm{A}, \mathrm{B}, \mathrm{C}) \leftrightarrow \mathrm{M}$ Test 2} \\
\hline & \multicolumn{3}{|c|}{$(\mathrm{A}, \mathrm{B}, \mathrm{C}) \rightarrow \mathrm{M}$} & \multicolumn{3}{|c|}{$\mathrm{M} \rightarrow(\mathrm{A}, \mathrm{B}, \mathrm{C})$} & \multicolumn{3}{|c|}{$(\mathrm{A}, \mathrm{B}, \mathrm{C}) \rightarrow \mathrm{M}$} & \multicolumn{3}{|c|}{$\mathrm{M} \rightarrow(\mathrm{A}, \mathrm{B}, \mathrm{C})$} \\
\hline & $1+$ & $2+$ & $M$ & $1+$ & $2+$ & $M$ & $1+$ & $2+$ & $M$ & $1+$ & $2+$ & $M$ \\
\hline Bird 1 & 56 & 61 & 58 & 86 & 72 & 7 & 86 & 70 & 78 & 86 & 86 & 86 \\
\hline Bird 3 & 78 & 81 & 79 & 78 & 89 & 83 & - & - & - & - & - & - \\
\hline Bird 4 & 58 & 53 & 56 & 47 & 53 & 50 & 75 & 89 & 82 & 78 & 78 & 78 \\
\hline Mean & 64 & 65 & 65 & 70 & 71 & 71 & 81 & 80 & 81 & 82 & 82 & 82 \\
\hline
\end{tabular}

Note- $1+$ indicates that Set 1 is positive and Set 2 is negative on training trials. $2+$ indicates that Set 1 is negative and Set 2 is positive on training trials. Mean test performances significantly better than chance $(p<.05)$ are shown in boldface.

8 blocks of 72 trials, respectively, to reach the criterion described above. They were then tested for transfer to the prototypes. Performance accuracy on probe trials in the $(\mathrm{A}, \mathrm{B}, \mathrm{C}) \rightarrow \mathrm{M}$ transfer test was $51 \%$ for Bird 5 and $54 \%$ for Bird 6.

Birds 7 and 8 were given discrimination training with the prototypes (M1 vs. M2) following the completion of discrimination training with the good exemplars. Choice accuracy in the first 72 -trial block was $97 \%$ and $99 \%$ for Birds 7 and 8, respectively. Training with the good exemplars thus resulted a high level of transfer to the prototypes, a finding similar to that of the prototype effect noted earlier. Discrimination training with the prototypes was ended after three sessions (a total of three blocks of 72 trials), and the pigeons were then tested for transfer to the poor exemplars. Performance accuracy on probe trials in the $\mathrm{M} \rightarrow(\mathrm{A}, \mathrm{B}, \mathrm{C})$ transfer test was $61 \%$ for Bird 7 and $57 \%$ for Bird 8 .

\section{Discussion}

The control group pigeons performed at or slightly above chance on probe trials in the $(\mathrm{A}, \mathrm{B}, \mathrm{C}) \rightarrow \mathrm{M}$ and $\mathrm{M} \rightarrow$ $(\mathrm{A}, \mathrm{B}, \mathrm{C})$ transfer tests $(56 \%$ correct on average $)$ - that is, the poor exemplars and the prototype of the same sets are not perceptually similar for pigeons. This confirms that the emergence of untrained $(\mathrm{A}, \mathrm{B}, \mathrm{C}) \leftrightarrow \mathrm{M}$ relation exhibited by the experimental group pigeons was not based on perceptual similarity between the poor exemplars and the prototype that appeared within the same test session.

The emergence of $(\mathrm{A}, \mathrm{B}, \mathrm{C}) \leftrightarrow \mathrm{M}$ equivalence shown by Bird 3 without $(\mathrm{A}, \mathrm{B}, \mathrm{C}) \leftrightarrow(\mathrm{AM}, \mathrm{BM}, \mathrm{CM})$ and (AM, $\mathrm{BM}, \mathrm{CM}) \leftrightarrow \mathrm{M}$ training is puzzling. Bird 3 first received the $(\mathrm{A}, \mathrm{B}, \mathrm{C}) \rightarrow \mathrm{M}$ test and then the $\mathrm{M} \rightarrow(\mathrm{A}, \mathrm{B}, \mathrm{C})$ test, so this pigeon had never seen the prototypes before the $(A$, $\mathrm{B}, \mathrm{C}) \rightarrow \mathrm{M}$ test. What is clear is that the learned equivalences among the good exemplars and the subsequent equivalence training with the poor exemplars conducted during the $(\mathrm{A}, \mathrm{B}, \mathrm{C}) \rightarrow \mathrm{M}$ test resulted in the emergence of $(A, B, C) \leftrightarrow M$ equivalence. One possible explanation for this is that the poor exemplars and the prototype were interrelated immediately through the good exemplars on the basis of perceptual similarities. The emergence of this transitive relation is truly perceptual because it occurs with no sharing of covarying functions between the poor and the good exemplars or between the good exemplars and the prototype. Although interesting, this issue is outside the scope of the present study. Another possibility is that Bird 3 had abstracted the prototype (M) from the good exemplars (AM, BM, and CM) and then $M$ was functionally related to the poor exemplars $(\mathrm{A}, \mathrm{B}$, and $\mathrm{C})$ through the corresponding good exemplars from which the prototype had been derived. It is not clear why Bird 1, which had first received the $(A, B, C) \rightarrow M$ test and then the $M \rightarrow(A$, $\mathrm{B}, \mathrm{C})$ test, passed only the latter test. A straightforward account may be that this pigeon also might have abstracted the prototype, but its performance during the $(\mathrm{A}, \mathrm{B}, \mathrm{C}) \rightarrow \mathrm{M}$ test deteriorated to some extent because it had never actually seen the prototypes before.

In light of the prototype abstraction discussed above, one may argue that the "emergent" performances shown by Birds 1 and 4 in $(A, B, C) \leftrightarrow M$ Test 2 had been indirectly learned during the preceding $(\mathrm{A}, \mathrm{B}, \mathrm{C}) \leftrightarrow(\mathrm{AM}, \mathrm{BM}$, $\mathrm{CM}$ ) training. In any event, what is now clear is that family resemblances among various members of a class enable pigeons to derive untrained functional equivalence relations between perceptually dissimilar members of the class.

\section{EXPERIMENT 3}

In Experiment 3, the pigeons in the experimental group, including Bird 2 from Experiment 1, were explicitly trained to form functional equivalence classes consisting of the prototype, the good exemplars, and the poor exemplars. The pigeons were then tested to examine whether or not they had actually learned equivalences among the poor exemplars that had been trained but never tested in Experiment 2.

\section{Method}

\section{Subjects, Stimuli, and Apparatus}

The 4 pigeons in the experimental group, including Bird 2 from Experiment 1, served as subjects. The stimuli and apparatus were as in Experiment 2.

\section{Procedure}

(A, B, C, AM, BM, CM, M) equivalence training. About 8 months after Experiment 2 was completed, the pigeons, including Bird 2 from Experiment 1, were explicitly trained to learn equivalences among the prototype, the good exemplars, and the poor ex- 
emplars. A series of reversals using all possible stimulus pairs was given. A session consisted of one or more blocks of 98 trials (98 stimulus configurations, including controls for position). Training continued until $80 \%$ or more correct responses were obtained during the first blocks following each of two successive reversals.

$(\mathbf{A}, \mathbf{B}, \mathbf{C}) \leftrightarrow \mathbf{M}$ test. This test phase was introduced to confirm that all the pigeons, including Bird 2, had learned the equivalence between the poor exemplars and the prototype. Procedural details were as in the (A, B, C) $\leftrightarrow \mathrm{M}$ tests in Experiment 2, except that nondifferential reinforcement was given on probe trials regardless of the pigeons' choice responses. Note that this procedure was used in all the following tests in this study.

$\mathbf{A} \leftrightarrow \mathbf{B}, \mathbf{B} \leftrightarrow \mathbf{C}$, and $\mathbf{C} \leftrightarrow \mathbf{A}$ tests. Testing sessions were designed to determine whether the pigeons actually learned the equivalences among the poor exemplars. As before, the test for $\mathrm{A} \leftrightarrow \mathrm{B}$ equivalence consisted of an $\mathrm{A} \rightarrow \mathrm{B}$ test and a $\mathrm{B} \rightarrow \mathrm{A}$ test. For the $\mathrm{A} \rightarrow \mathrm{B}$ test, for example, the training and probe pairs were $\mathrm{A} 1 \mathrm{~A} 2$ and $\mathrm{B} 1 \mathrm{~B} 2$, respectively. The reinforcement allocation of the training pair was reversed between two successive test sessions. A test block consisted of 54 training trials and 18 randomly inserted probe trials. A total of 12 test sessions were given (2 successive sessions for each of the $A \rightarrow B$, $\mathrm{B} \rightarrow \mathrm{A}, \mathrm{B} \rightarrow \mathrm{C}, \mathrm{C} \rightarrow \mathrm{B}, \mathrm{C} \rightarrow \mathrm{A}$, and $\mathrm{A} \rightarrow \mathrm{C}$ tests). The order of the $\mathrm{A} \leftrightarrow \mathrm{B}$, $\mathrm{B} \leftrightarrow \mathrm{C}$, and $\mathrm{C} \leftrightarrow \mathrm{A}$ tests was balanced across pigeons.

\section{Results and Discussion}

Birds 1, 2, 3, and 4 completed the (A, B, C, AM, BM, $\mathrm{CM}, \mathrm{M})$ equivalence training after $18,93,40$, and 34 reversals, respectively. Bird 2 required numerous sessions to reverse choices after reversals but eventually learned to switch choices soon after reversals. Even about 8 months after the completion of Experiment 2, the pigeons that had served as subjects (Birds 1, 3, and 4) required fewer reversals than did Bird 2 to attain the reversal criterion mentioned above.

\section{$(A, B, C) \leftrightarrow M$ Test}

The respective percent correct choices on probe trials in the $(\mathrm{A}, \mathrm{B}, \mathrm{C}) \rightarrow \mathrm{M}$ and $\mathrm{M} \rightarrow(\mathrm{A}, \mathrm{B}, \mathrm{C})$ tests were $82 \%$ and $72 \%, 79 \%$ and $85 \%, 76 \%$ and $79 \%$, and $90 \%$ and $74 \%$ for Birds 1, 2, 3, and 4, respectively. As before, we evaluated the test results in terms of whether the binomial distribution score was significantly above chance $(p<.05)$. The pigeons, including Bird 2, passed the test for the (A, B, C) $\leftrightarrow$ M equivalence.

\section{$\mathrm{A} \leftrightarrow \mathrm{B}, \mathrm{B} \leftrightarrow \mathrm{C}$, and $\mathrm{C} \leftrightarrow \mathrm{A}$ Tests}

Table 3 shows the results from the $\mathrm{A} \leftrightarrow \mathrm{B}, \mathrm{B} \leftrightarrow \mathrm{C}$, and $\mathrm{C} \leftrightarrow$ A tests. Birds 1 and 4 passed the test for the $\mathrm{A} \leftrightarrow \mathrm{C}$ equiva- lence, and Bird 2 passed the test for the $\mathrm{B} \leftrightarrow \mathrm{C}$ equivalence. However, Birds 1 and 4 had considerable difficulty in reversing their responses to these test stimuli when contingencies for the training stimuli were reversed. During the $\mathrm{A} \rightarrow \mathrm{C}$ test, Bird 1 was correct $56 \%$ and $94 \%$ of the time and Bird 4 was correct $94 \%$ and $50 \%$ of the time in the Type $1+$ and Type $2+$ test sessions, respectively. A similar tendency can be seen for the $\mathrm{B} \rightarrow \mathrm{C}$ conditional relation shown by Bird 1 and the $\mathrm{B} \rightarrow \mathrm{A}$ conditional relation shown by Bird 4. Surprisingly, Bird 3 performed poorly in all the tests, although this pigeon had quickly reversed responses to the poor exemplar pairs in the first postreversal training block during the $(\mathrm{A}, \mathrm{B}, \mathrm{C}) \rightarrow \mathrm{M}$ test in Experiment 2. All in all, we have to conclude that the pigeons failed to relate the poor exemplars by equivalence, despite the extensive training carried out in Experiments 2 and 3.

Although we used all female or all male face pictures in an attempt to increase perceptual similarity among the poor exemplars, this did not allow the pigeons to learn equivalences among the poor exemplars. A related implication of the results concerns the failure to interrelate the poor exemplars through transitivity. For example, A and $\mathrm{B}$ were to be equivalent through $\mathrm{A} \leftrightarrow \mathrm{M}$ and $\mathrm{M} \leftrightarrow \mathrm{B}$ and also through $\mathrm{A} \leftrightarrow \mathrm{AM}, \mathrm{AM} \leftrightarrow \mathrm{BM}$, and $\mathrm{BM} \leftrightarrow \mathrm{B}$. However, the pigeons failed to learn the equivalence even though all these stimuli were included in the (A, B, C, AM, BM, CM, $\mathrm{M})$ class formation training of the present experiment.

It should be noted here that, after completion of Experiment 3 , a series of equivalence tests was conducted to ensure that the pigeons, including Bird 2, had learned $\mathrm{AM} \leftrightarrow \mathrm{BM}, \mathrm{BM} \leftrightarrow \mathrm{CM}, \mathrm{CM} \leftrightarrow \mathrm{AM},(\mathrm{A}, \mathrm{B}, \mathrm{C}) \leftrightarrow(\mathrm{AM}, \mathrm{BM}$, $\mathrm{CM})$, and (AM, BM, CM) $\leftrightarrow$ M equivalences, all of which were extensively trained or tested during Experiments 1 and 2. All the pigeons, including Bird 2, passed all the tests. Figure 3 summarizes the results of the tests, together with those of Experiments 2 and 3. The pigeons learned that the poor exemplars were equivalent to the good exemplars as well as to the prototype. Nevertheless, they failed to relate the poor exemplars as members of the same functional class in Experiment 3.

\section{EXPERIMENT 4}

In Experiment 4, 50\% morphs of the poor exemplars$\mathrm{AB} 1, \mathrm{BC} 1$, and $\mathrm{CA} 1$ in Set 1 and $\mathrm{AB} 2, \mathrm{BC} 2$, and $\mathrm{CA} 2$ in

Table 3

Percent Correct Responses to Probe Pairs on the $A \leftrightarrow B, B \leftrightarrow C$, and $C \leftrightarrow A$ Tests in Experiment 3

\begin{tabular}{|c|c|c|c|c|c|c|c|c|c|c|c|c|c|c|c|c|c|c|}
\hline \multirow[b]{3}{*}{ Subject } & \multicolumn{6}{|c|}{$\mathrm{A} \leftrightarrow \mathrm{B}$} & \multicolumn{6}{|c|}{$\mathrm{B} \leftrightarrow \mathrm{C}$} & \multicolumn{6}{|c|}{$\mathrm{C} \leftrightarrow \mathrm{A}$} \\
\hline & \multicolumn{3}{|c|}{$\mathrm{A} \rightarrow \mathrm{B}$} & \multicolumn{3}{|c|}{$\mathrm{B} \rightarrow \mathrm{A}$} & \multicolumn{3}{|c|}{$\mathrm{B} \rightarrow \mathrm{C}$} & \multicolumn{3}{|c|}{$\mathrm{C} \rightarrow \mathrm{B}$} & \multicolumn{3}{|c|}{$\mathrm{C} \rightarrow \mathrm{A}$} & \multicolumn{3}{|c|}{$\mathrm{A} \rightarrow \mathrm{C}$} \\
\hline & $1+$ & $2+$ & $M$ & $1+$ & $2+$ & $M$ & $1+$ & $2+$ & $M$ & $1+$ & $2+$ & $M$ & $1+$ & $2+$ & $M$ & $1+$ & $2+$ & $M$ \\
\hline Bird 1 & 22 & 77 & 50 & 61 & 61 & 61 & 94 & 67 & 81 & 11 & 100 & 56 & 72 & 88 & 81 & 56 & 94 & 75 \\
\hline Bird 2 & 83 & 83 & 83 & 67 & 72 & 69 & 83 & 72 & 78 & 89 & 89 & 89 & 50 & 61 & 56 & 78 & 72 & 75 \\
\hline Bird 3 & 61 & 50 & 56 & 83 & 17 & 50 & 61 & 56 & 58 & 50 & 83 & 67 & 78 & 61 & 69 & 67 & 72 & 69 \\
\hline Bird 4 & 72 & 56 & 64 & 67 & 78 & 72 & 78 & 83 & 81 & 89 & 33 & 61 & 100 & 83 & 92 & 94 & 50 & 72 \\
\hline Mean & 60 & 67 & 63 & 70 & 57 & 63 & 79 & 70 & 75 & 60 & 76 & 68 & 75 & 73 & 74 & 74 & 72 & 73 \\
\hline
\end{tabular}

Note $-1+$ indicates that Set 1 is positive and Set 2 is negative on training trials. $2+$ indicates that Set 1 is negative and Set 2 is positive on training trials. Mean test performances significantly better than chance $(p<.05)$ are shown in boldface. 


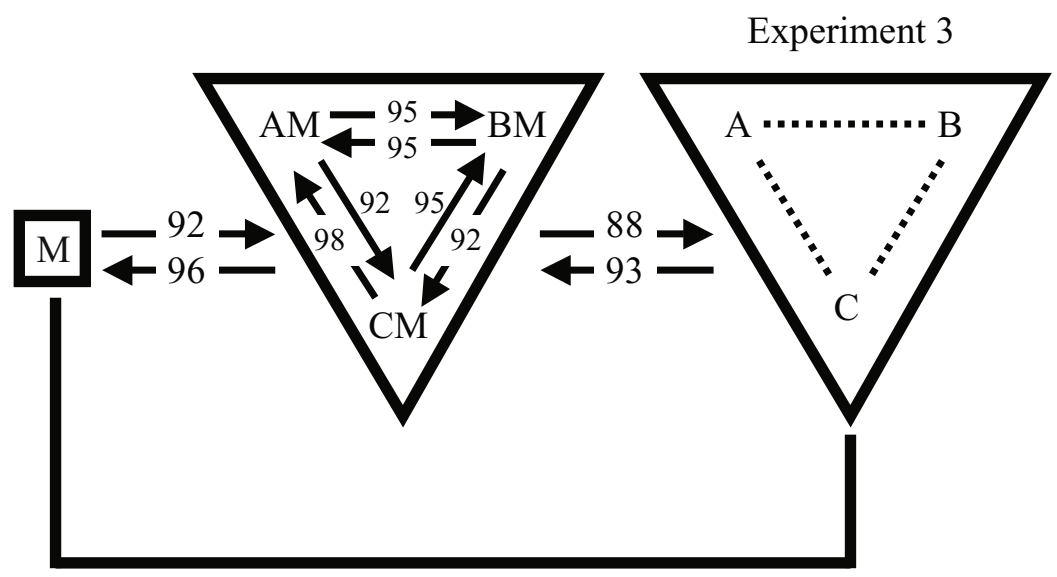

Experiments 2, 3

Figure 3. The test results in $A M \leftrightarrow B M, B M \leftrightarrow C M, C M \leftrightarrow A M,(A, B, C) \leftrightarrow(A M, B M$, $C M)$ and $(A M, B M, C M) \leftrightarrow M$ tests conducted after completion of Experiment 3. The numbers are the test percent correct scores averaged among the 4 pigeons. The solid line indicates that $M$ and (A, B, C) were related by equivalence (Experiments 2 and 3). Broken lines indicate that the poor exemplars were not fully related to one another by equivalence (Experiment 3).

Set 2-were introduced to examine whether or not perceptual transitivity would make it easier for the pigeons to learn equivalences among the poor exemplars (A, B, and $\mathrm{C}$ ). On the basis of the finding of Experiment 2 that an untrained $\mathrm{M} \leftrightarrow(\mathrm{A}, \mathrm{B}, \mathrm{C})$ equivalence emerged from the trained $\mathrm{M} \leftrightarrow(\mathrm{AM}, \mathrm{BM}, \mathrm{CM})$ and $(\mathrm{AM}, \mathrm{BM}, \mathrm{CM}) \leftrightarrow(\mathrm{A}, \mathrm{B}$, C) equivalences, we expected that the pigeons would possibly learn that the poor exemplars were equivalent to one another by class formation training with all the exemplars, including $\mathrm{AB}, \mathrm{BC}$, and $\mathrm{CA}$.

\section{Method \\ Subjects and Apparatus \\ The subjects and apparatus were the same as in Experiment 3. \\ Stimuli \\ New stimuli were created as $50 \%$ morphs of the poor exemplars. They were $50 \% \mathrm{~A} 50 \% \mathrm{~B}(\mathrm{AB} 1$ and $\mathrm{AB} 2), 50 \% \mathrm{~B} 50 \% \mathrm{C}(\mathrm{BC} 1$ and $\mathrm{BC} 2$ ), and $50 \% \mathrm{C} 50 \% \mathrm{~A}(\mathrm{CA} 1$ and $\mathrm{CA} 2)$. Other stimuli were the same as in Experiment 3.}

\section{Procedure}

(A, B, C, AB, BC, CA, AM, BM, CM, M) equivalence training. Class formation training was conducted with all the exemplars, including the newly introduced $50 \%$ morphs of the poor exemplars. A series of reversals was given using AM1AM2, BM1BM2, $\mathrm{CM} 1 \mathrm{CM} 2, \mathrm{M} 1 \mathrm{M} 2, \mathrm{~A} 1 \mathrm{~A} 2, \mathrm{~B} 1 \mathrm{~B} 2, \mathrm{C} 1 \mathrm{C} 2, \mathrm{AB} 1 \mathrm{AB} 2, \mathrm{BC} 1 \mathrm{BC} 2$, and CA1CA2. A session consisted of one or more blocks of 80 trials (four repeats of 20 stimulus configurations, including controls for position). Training continued until $80 \%$ or more correct responses were obtained during the first blocks following each of two successive reversals.

$\mathbf{A} \leftrightarrow \mathbf{B}, \mathbf{B} \leftrightarrow \mathbf{C}$, and $\mathbf{C} \leftrightarrow \mathbf{A}$ tests. After completion of the equivalence training, $A \leftrightarrow B, B \leftrightarrow C$, and $C \leftrightarrow A$ tests were given. The procedural details were as in Experiment 3.

\section{Results and Discussion}

Birds 1, 2, and 4 completed the (A, B, C, AB, BC, CA, $\mathrm{AM}, \mathrm{BM}, \mathrm{CM}, \mathrm{M}$ ) equivalence training after 14,5 , and 4 reversals, respectively. Bird 3 showed difficulty with reversals, requiring 77 to complete the reversal training. Recall that Bird 3 did not receive $(\mathrm{A}, \mathrm{B}, \mathrm{C}) \leftrightarrow(\mathrm{AM}, \mathrm{BM}$, $\mathrm{CM}$ ) training in Experiment 2. It is possible that the subsequent (A, B, C, AM, BM, CM, M) class formation training in Experiment 3 was insufficient for this pigeon to learn equivalences among $\mathrm{A}, \mathrm{B}$, and $\mathrm{C}$, although this pigeon had been given equivalence training with the poor exemplars during the $(\mathrm{A}, \mathrm{B}, \mathrm{C}) \leftrightarrow \mathrm{M}$ test in Experiment 2 .

As is shown in Table 4, all the pigeons passed all the tests. Thus, class formation training, including training with the $50 \%$ morphs of the poor exemplars, enabled the pigeons to learn equivalences among the poor exemplars. Note also that the pigeons generally performed accurately on probe trials in $1+$ and $2+$ test sessions, except in the $\mathrm{A} \rightarrow \mathrm{B}$ and $\mathrm{B} \rightarrow \mathrm{A}$ tests for Bird 2 and the $\mathrm{B} \rightarrow \mathrm{C}$ test for Bird 3. A two-way repeated measures ANOVA with experiment (Experiment 3 vs. Experiment 4) and equivalence relation $(A \leftrightarrow B$ vs. $B \leftrightarrow C$ vs. $C \leftrightarrow A)$ as variables was conducted on the mean performance scores shown in Tables 3 and 4. Only the effect of experiment was significant $[F(1,3)=9.64, p=.05]$. It follows from this analysis that the formation of functional equivalences among physically dissimilar exemplars is related to the other members of the class that were used together in class formation training.

However, the facilitation effect shown by Bird 3 may simply have reflected additional training with just the poor exemplars $(\mathrm{A}, \mathrm{B}$, and $\mathrm{C})$ used during the $(\mathrm{A}, \mathrm{B}, \mathrm{C}$, 
Table 4

Percent Correct Responses to Probe Pairs on the $A \leftrightarrow B, B \leftrightarrow C$, and $C \leftrightarrow A$ Tests in Experiment 4

\begin{tabular}{|c|c|c|c|c|c|c|c|c|c|c|c|c|c|c|c|c|c|c|}
\hline \multirow[b]{3}{*}{ Subject } & \multicolumn{6}{|c|}{$\mathrm{A} \leftrightarrow \mathrm{B}$} & \multicolumn{6}{|c|}{$\mathrm{B} \leftrightarrow \mathrm{C}$} & \multicolumn{6}{|c|}{$\mathrm{C} \leftrightarrow \mathrm{A}$} \\
\hline & \multicolumn{3}{|c|}{$\mathrm{A} \rightarrow \mathrm{B}$} & \multicolumn{3}{|c|}{$\mathrm{B} \rightarrow \mathrm{A}$} & \multicolumn{3}{|c|}{$\mathrm{B} \rightarrow \mathrm{C}$} & \multicolumn{3}{|c|}{$\mathrm{C} \rightarrow \mathrm{B}$} & \multicolumn{3}{|c|}{$\mathrm{C} \rightarrow \mathrm{A}$} & \multicolumn{3}{|c|}{$\mathrm{A} \rightarrow \mathrm{C}$} \\
\hline & $1+$ & $2+$ & $\bar{M}$ & $1+$ & $2+$ & $\bar{M}$ & $1+$ & $2+$ & $\bar{M}$ & $1+$ & $2+$ & $\bar{M}$ & $1+$ & $2+$ & $\bar{M}$ & $1+$ & $2+$ & $\bar{M}$ \\
\hline Bird 1 & 83 & 78 & 81 & 89 & 89 & 89 & 83 & 100 & 92 & 89 & 100 & 94 & 83 & 89 & 86 & 100 & 83 & 92 \\
\hline Bird 2 & 61 & 89 & 75 & 67 & 83 & 75 & 72 & 94 & 83 & 83 & 78 & 81 & 78 & 78 & 78 & 72 & 83 & 78 \\
\hline Bird 3 & 89 & 94 & 92 & 83 & 94 & 89 & 67 & 83 & 75 & 78 & 78 & 78 & 78 & 83 & 81 & 78 & 89 & 83 \\
\hline Bird 4 & 83 & 94 & 89 & 100 & 78 & 89 & 83 & 78 & 81 & 89 & 72 & 81 & 83 & 78 & 81 & 89 & 83 & 86 \\
\hline Mean & 79 & 89 & 84 & 85 & 86 & 86 & 76 & 89 & 83 & 85 & 82 & 84 & 81 & 82 & 82 & 85 & 85 & 85 \\
\hline
\end{tabular}

Note-1+ indicates that Set 1 is positive and Set 2 is negative on training trials. $2+$ indicates that Set 1 is negative and Set 2 is positive on training trials. Mean test performances significantly better than chance $(p<.05)$ are shown in boldface.

$\mathrm{AB}, \mathrm{BC}, \mathrm{CA}, \mathrm{AM}, \mathrm{BM}, \mathrm{CM}, \mathrm{M}$ ) equivalence training. As noted above, this pigeon required 77 reversals to complete training. The remaining pigeons required only 14,5 , and 4 reversals. In light of the extensive reversal training given with the poor exemplars in the previous experimental stages (Experiments 2 and 3), it is rather difficult to consider that the very small number of reversals given to these pigeons in Experiment 4 had an effect of the continuation of explicitly trained relations.

\section{EXPERIMENT 5}

Experiment 5 was designed to examine whether or not the pigeons actually learned that the newly introduced poor exemplars $\mathrm{AB}, \mathrm{BC}$, and $\mathrm{CA}$ were equivalent to physically dissimilar members of the class. More specifically, we tested the formation of $(\mathrm{AB}, \mathrm{BC}, \mathrm{CA}) \leftrightarrow \mathrm{M}$ equivalence and $\mathrm{AB} \leftrightarrow \mathrm{C}, \mathrm{BC} \leftrightarrow \mathrm{A}$, and $\mathrm{CA} \leftrightarrow \mathrm{B}$ equivalences. Note that the training and test stimuli in these tests were not directly related by straightforward perceptual transitivity. As was demonstrated in Experiment 3, repeated reversal training alone is not always sufficient for learning functional equivalences between distantly related exemplars. It was thus necessary to examine whether or not the pigeons successfully learned to relate the newly introduced stimuli to the other members of the class.

\section{Method \\ Subjects, Apparatus, and Stimuli}

The subjects, apparatus, and stimuli were as in Experiment 4.

\section{Procedure}

The pigeons received (A, B, C, AB, BC, CA, AM, BM, CM, M) equivalence training as in Experiment 4 until they regained the reversal criterion mentioned above. They were then given $(\mathrm{AB}, \mathrm{BC}$, $\mathrm{CA}) \leftrightarrow \mathrm{M}, \mathrm{AB} \leftrightarrow \mathrm{C}, \mathrm{BC} \leftrightarrow \mathrm{A}$, and $\mathrm{CA} \leftrightarrow \mathrm{B}$ tests. Testing order was balanced among the pigeons.

$(\mathbf{A B}, \mathbf{B C}, \mathbf{C A}) \leftrightarrow \mathbf{M}$ test. Procedural details were as in the (A, $\mathrm{B}, \mathrm{C}) \leftrightarrow \mathrm{M}$ test except that $\mathrm{AB}, \mathrm{BC}$, and $\mathrm{CA}$ were used instead of $\mathrm{A}, \mathrm{B}$, and $\mathrm{C}$.

$\mathbf{A B} \leftrightarrow \mathbf{C}, \mathbf{B C} \leftrightarrow \mathbf{A}$, and $\mathbf{C A} \leftrightarrow \mathbf{B}$ tests. Procedural details were as in the $\mathrm{A} \leftrightarrow \mathrm{B}, \mathrm{B} \leftrightarrow \mathrm{C}$, and $\mathrm{C} \leftrightarrow \mathrm{A}$ tests except that $\mathrm{AB}, \mathrm{BC}$, and $\mathrm{CA}$ served on training trials in the $\mathrm{AB} \rightarrow \mathrm{C}, \mathrm{BC} \rightarrow \mathrm{A}$, and $\mathrm{CA} \rightarrow \mathrm{B}$ tests, respectively, and on probe trials in the $\mathrm{C} \rightarrow \mathrm{AB}, \mathrm{A} \rightarrow \mathrm{BC}$, and $\mathrm{B} \rightarrow \mathrm{CA}$ tests, respectively.

\section{Results and Discussion}

Table 5 shows the findings of the $(\mathrm{AB}, \mathrm{BC}, \mathrm{CA}) \leftrightarrow \mathrm{M}$ test. All the pigeons passed all the tests. The pigeons had no difficulty in reversing their responses to test stimuli according to the contingencies that were in effect on training trials, as is indicated by their accurate performance in $1+$ and $2+$ test sessions.

Table 6 shows the results of the $\mathrm{A} \leftrightarrow \mathrm{BC}, \mathrm{B} \leftrightarrow \mathrm{AC}$, and $\mathrm{C} \leftrightarrow \mathrm{AB}$ tests. Again, all the pigeons passed all the tests. However, Bird 4 showed considerable difficulty in reversing responses to test stimuli during the $\mathrm{B} \rightarrow \mathrm{AC}, \mathrm{C} \rightarrow \mathrm{AB}$, and $\mathrm{AB} \rightarrow \mathrm{C}$ tests. Similarly, Bird 1's reversal performances were not highly accurate during the $\mathrm{A} \rightarrow \mathrm{BC}$ and $\mathrm{BC} \rightarrow \mathrm{A}$ tests. The stimuli that served as training and test stimuli in these tests might have been only weakly related to one another and, therefore, the most recently valid contingency that had been applied for test stimuli adversely affected test trial accuracy for these pigeons.

In the tests carried out in the present experiment, correct responses on the probe trials could be determined neither by physical similarity between the training and test pairs nor by straightforward perceptual transitivity of the kind that occurred among the poor exemplars such as "if $\mathrm{A} \leftrightarrow \mathrm{AB}$ and $\mathrm{AB} \leftrightarrow \mathrm{B}$, then $\mathrm{A} \leftrightarrow \mathrm{B}$." Nevertheless, the newly introduced poor exemplars had been incorporated into the preexisting functional equivalence classes, although Birds 1 and 4 only weakly related some of the newly introduced exemplars to the classes.

Table 5

Percent Correct Responses to Probe Pairs on the $(A B, B C, C A) \leftrightarrow M$ Test in Experiment 5

\begin{tabular}{llllllll}
\hline & \multicolumn{3}{c}{$(\mathrm{AB}, \mathrm{BC}, \mathrm{CA}) \rightarrow \mathrm{M}$} & & \multicolumn{3}{c}{$\mathrm{M} \rightarrow(\mathrm{AB}, \mathrm{BC}, \mathrm{CA})$} \\
\cline { 2 - 3 } Subject & $1+$ & $2+$ & $M$ & & $1+$ & $2+$ & $M$ \\
\hline Bird 1 & 94 & 92 & $\mathbf{9 3}$ & & 75 & 83 & $\mathbf{7 9}$ \\
Bird 2 & 83 & 83 & $\mathbf{8 3}$ & & 77 & 81 & $\mathbf{7 9}$ \\
Bird 3 & 97 & 97 & $\mathbf{9 7}$ & & 81 & 89 & $\mathbf{8 5}$ \\
Bird 4 & 97 & 97 & $\mathbf{9 7}$ & 72 & 81 & $\mathbf{7 6}$ \\
Mean & 93 & 92 & $\mathbf{9 3}$ & 76 & 84 & $\mathbf{8 0}$ \\
\hline
\end{tabular}

Note $-1+$ indicates that Set 1 is positive and Set 2 is negative on training trials. $2+$ indicates that Set 1 is negative and Set 2 is positive on training trials. Mean test performances significantly better than chance $(p<.05)$ are shown in boldface. 
Table 6 Percent Correct Responses to Probe Pairs on the $A \leftrightarrow B C, B \leftrightarrow A C$, and $C \leftrightarrow A B$ 'lests in Experiment 5

\begin{tabular}{|c|c|c|c|c|c|c|c|c|c|c|c|c|c|c|c|c|c|c|}
\hline \multirow[b]{3}{*}{ Subject } & \multicolumn{6}{|c|}{$\mathrm{A} \leftrightarrow \mathrm{BC}$} & \multicolumn{6}{|c|}{$\mathrm{B} \leftrightarrow \mathrm{AC}$} & \multicolumn{6}{|c|}{$\mathrm{C} \leftrightarrow \mathrm{AB}$} \\
\hline & \multicolumn{3}{|c|}{$\mathrm{A} \rightarrow \mathrm{BC}$} & \multicolumn{3}{|c|}{$\mathrm{BC} \rightarrow \mathrm{A}$} & \multicolumn{3}{|c|}{$\mathrm{B} \rightarrow \mathrm{AC}$} & \multicolumn{3}{|c|}{$\mathrm{AC} \rightarrow \mathrm{B}$} & \multicolumn{3}{|c|}{$\mathrm{C} \rightarrow \mathrm{AB}$} & \multicolumn{3}{|c|}{$\mathrm{AB} \rightarrow \mathrm{C}$} \\
\hline & $1+$ & $2+$ & $M$ & $1+$ & $2+$ & $M$ & $1+$ & $2+$ & $M$ & $1+$ & $2+$ & $M$ & $1+$ & $2+$ & $M$ & $1+$ & $2+$ & $M$ \\
\hline Bird 1 & 100 & 44 & 72 & 67 & 100 & 83 & 78 & 72 & 75 & 89 & 89 & 89 & 83 & 89 & 86 & 89 & 83 & 86 \\
\hline Bird 2 & 78 & 83 & 81 & 100 & 100 & 100 & 72 & 94 & 83 & 89 & 100 & 94 & 72 & 77 & 75 & 72 & 83 & 78 \\
\hline Bird 3 & 100 & 89 & 94 & 100 & 67 & 83 & 94 & 100 & 97 & 100 & 100 & 100 & 100 & 94 & 97 & 100 & 100 & 100 \\
\hline Bird 4 & 72 & 78 & 75 & 100 & 83 & 92 & 83 & 61 & 72 & 89 & 72 & 81 & 94 & 67 & 81 & 83 & 67 & 75 \\
\hline Mean & 88 & 74 & 81 & 92 & 88 & 90 & 82 & 82 & 82 & 92 & 90 & 91 & 87 & 82 & 85 & 86 & 83 & 85 \\
\hline
\end{tabular}

Note- $1+$ indicates that Set 1 is positive and Set 2 is negative on training trials. $2+$ indicates that Set 1 is negative and Set 2 is positive on training trials. Mean test performances significantly better than chance $(p<.05)$ are shown in boldface.

Sidman (1994, p. 452) pointed out that discrimination reversal training involves a conditional discrimination between two positive stimuli appearing on successive trials. However, it is unlikely that, during the $(\mathrm{A}, \mathrm{B}, \mathrm{C}, \mathrm{AB}$, $\mathrm{BC}, \mathrm{CA}, \mathrm{AM}, \mathrm{BM}, \mathrm{CM}, \mathrm{M})$ equivalence training the pigeons (except Bird 3, which required 77 reversals in Experiment 4) simply learned a large number of unrelated conditional discriminations between the newly introduced poor exemplars and the other members of the class (48 conditional relations, including those between the newly introduced poor exemplars within each class) as well as those between $\mathrm{A}, \mathrm{B}$, and $\mathrm{C}$, which they had failed to show after the previous (A, B, C, AM, BM, CM, M) equivalence training. It may be that resemblances among the various exemplars that were used together in the $(\mathrm{A}, \mathrm{B}, \mathrm{C}, \mathrm{AB}, \mathrm{BC}$, $\mathrm{CA}, \mathrm{AM}, \mathrm{BM}, \mathrm{CM}, \mathrm{M}$ ) equivalence training might have played an important role in bringing the new poor exemplars into the preexisting functional equivalence classes. We can conclude that the pigeons eventually learned the equivalence network consisting of the various exemplars that were internally related through family resemblances.

\section{GENERAL DISCUSSION}

The main aim of the present study was to investigate how pigeons learn functional equivalences among members of stimulus classes that are structured by family resemblances (see, e.g., Rosch, 1978; Rosch \& Mervis, 1975), rather than to explore the emergence of formal equivalences among arbitrary stimuli in the absence of direct training (see, e.g., Sidman, 1994; Sidman \& Tailby, 1982). The sequentially introduced training and testing phases successfully tracked expansion of the learned functional equivalence classes so as to include various exemplars that might have little similarity but could be linked together through other members of the class.

In Experiment 1, the pigeons were trained in the equivalence of good exemplars (AM, BM, and CM) that were substantially similar to one another yet potentially discriminable. In natural settings, good exemplars of a category may share both physical features (thus they look alike to one another) and stimulus functions. Control of behavior by perceptual similarity is of substantial relevance if animals are to respond appropriately in natural settings to various exemplars that bear a similarity to one another.
Having learned the $\mathrm{AM} \leftrightarrow \mathrm{BM}$ and $\mathrm{BM} \leftrightarrow \mathrm{CM}$ relations in repeated reversals, Birds 1, 3, and 4 then showed an untrained $\mathrm{AM} \leftrightarrow \mathrm{CM}$ relation. That is, these pigeons learned to switch their choices according to the contingencies of reinforcement applied to any of the perceptually similar stimuli. In the following experimental stages, we investigated whether or not the stimulus classes would expand to include new stimuli that were perceptually dissimilar to one another.

In Experiment 2, we explored the emergence of equivalence between the prototype (M) and the poor exemplars $(\mathrm{A}, \mathrm{B}$, and $\mathrm{C})$ with the pigeons tested in Experiment 1. One of the pigeons (Bird 3) related $\mathrm{M}$ and $(\mathrm{A}, \mathrm{B}, \mathrm{C})$ by equivalence without additional training. The remaining 2 pigeons showed the equivalence on the basis of the explicitly trained $\mathrm{M} \leftrightarrow(\mathrm{AM}, \mathrm{BM}, \mathrm{CM})$ and (AM, BM, $\mathrm{CM}) \leftrightarrow(\mathrm{A}, \mathrm{B}, \mathrm{C})$ equivalences, a finding reflecting perceptual transitivity of the kind "if $\mathrm{M} \leftrightarrow(\mathrm{AM}, \mathrm{BM}, \mathrm{CM})$ and $(\mathrm{AM}, \mathrm{BM}, \mathrm{CM}) \leftrightarrow(\mathrm{A}, \mathrm{B}, \mathrm{C})$, then $\mathrm{M} \leftrightarrow(\mathrm{A}, \mathrm{B}, \mathrm{C})$." Because the prototype and the poor exemplars were not perceptually similar, as confirmed by the control group pigeons' degraded generalizations, the emergent relation could not be explained by stimulus generalization. There was a possibility that the pigeons abstracted the prototype from the good exemplars and that the prototype and the poor exemplars were related to each other during (AM, $\mathrm{BM}, \mathrm{CM}) \leftrightarrow(\mathrm{A}, \mathrm{B}, \mathrm{C})$ training, but the findings, including those of Bird 3, indicated that pigeons are capable of relating perceptually dissimilar stimuli through already learned good exemplars that are perceptually similar to each of those stimuli.

In Experiment 3, the pigeons (Birds 1, 2, 3, and 4) were explicitly trained to form functional equivalence classes consisting of the good exemplars (AM, BM, and CM), the prototype $(\mathrm{M})$, and the poor exemplars (A, B, and C). Subsequent tests confirmed that the pigeons had learned that the poor exemplars were equivalent to the good exemplars as well as to the prototype. However, none of the pigeons fully learned the equivalences among the poor exemplars, despite extensive reversal training with the poor exemplars in the previous training and testing stages. We expected that transitive relations of the kind "if $A \leftrightarrow M$ and $\mathrm{M} \leftrightarrow \mathrm{B}$, then $\mathrm{A} \leftrightarrow \mathrm{B}$ " might facilitate the pigeons' learning of functional equivalences among the dissimilar poor exemplars, but this was not the case. It was also suggested 
that repeated reversal training alone is not always sufficient for pigeons to learn functional equivalences (see also Jitsumori et al., 2002).

In Experiment 4, new poor exemplars $(\mathrm{AB}, \mathrm{BC}$, and $\mathrm{CA})$ were introduced into the class formation training. Subsequent tests revealed that the poor exemplars A, B, and $\mathrm{C}$ became equivalent to one another. The result, together with those of Experiment 2, suggested that in natural settings perceptual transitivity may enable animals to cope with the inevitable variations that occur among the exemplars within a class. Furthermore, Experiment 5 revealed that the newly introduced poor exemplars had been related by equivalence to the prototype and even to the most distant preexisting poor exemplars (thus, $\mathrm{AB} \leftrightarrow \mathrm{C}$, $\mathrm{BC} \leftrightarrow \mathrm{A}$, and $\mathrm{CA} \leftrightarrow \mathrm{B})$. These findings suggested that the facilitation effect found in Experiment 4 was not due simply to the continuation of explicitly trained relations. The formation of functional equivalences among dissimilar stimuli was related to the other members of the class that were used together in class formation training.

Another important implication of the findings in Experiment 5 is that pigeons are able to learn functional equivalences between distantly related exemplars with ease. As we noted earlier, the stimuli that appeared on training and probe trials in Experiment 5 were not directly related by straightforward perceptual transitivity. The result led us to conclude that our pigeons had eventually learned the equivalence network consisting of the various exemplars. In such an equivalence network, exemplars that differ in various ways should be bound together. However, because the pigeons in the present study were explicitly trained to form the equivalence classes, subsequent research is needed to examine whether or not pigeons will be able to relate distantly related exemplars without any direct equivalence training.

What is still unclear in the present study is whether the repeated reversal procedure had indeed generated true partitions or the pigeons had learned a large number of conditional relations (see Sidman, 1994, p. 452), including the emergent relations that occurred transitively through explicitly trained multiple conditional relations. With regard to this issue, we have discussed that it is unlikely that during the (A, B, C, AB, BC, CA, AM, BM, CM, M) training, the pigeons (except Bird 3 ) simply learned a large number of unrelated conditional discriminations between the newly introduced poor exemplars and the other members of the class. However, this issue remains to be resolved in further experimentation. One obvious challenge will be to examine whether pigeons that have learned to relate a physically disparate stimulus (e.g., a tilted line) to a given exemplar by equivalence will transfer this relation quickly to the remaining exemplars of the class.

A possible limitation of this study is the difficulty in identifying the physical features actually used by pigeons to discriminate human face stimuli that vary along many dimensions (Huber, Troje, Loidolt, Aust, \& Grass, 2000; Jitsumori \& Makino, 2004; Troje, Huber, Loidolt, Aust, \& Fieder, 1999). It is therefore impossible to specify how the pigeons internally represented the equivalence classes consisting of human face stimuli. The human face categories used in this study were created by means of morphing, on the basis of the finding with pigeons (Makino \& Jitsumori, 2000) that $50 \%$ morphs of two faces are perceptually similar to each of the original faces but discriminably different from the originals. Although the artificial categories used in the present study were not created from identifiable features, the stimulus classes consisting of human face stimuli were indeed well structured by family resemblances. The findings at different experimental stages of this study are consistent in suggesting that family resemblances facilitate the formation and expansion of classes of functionally related stimuli by pigeons.

\section{REFERENCES}

Astley, S. L., \& Wasserman, E. A. (1998). Novelty and functional equivalence in superordinate categorization by pigeons. Animal Learning \& Behavior, 26, 125-138.

Astley, S. L., \& Wasserman, E. A. (1999). Superordinate category formation in pigeons: Association with a common delay or probability of food reinforcement makes perceptually dissimilar stimuli functionally equivalent. Journal of Experimental Psychology: Animal Behavior Processes, 25, 415-432.

Bhatt, R. S., \& Wasserman, E. A. (1989). Secondary generalization and categorization in pigeons. Journal of the Experimental Analysis of Behavior, 52, 213-224.

Bhatt, R. S., Wasserman, E. A., Reynolds, W. F., \& Knauss, K. S. (1988). Conceptual behavior in pigeons: Categorization of both familiar and novel examples from four classes of natural and artificial stimuli. Journal of Experimental Psychology: Animal Behavior Processes, 14, 219-234.

Brown, P. L., \& Jenkins, H. M. (1968). Auto-shaping of the pigeon's key-peck. Journal of the Experimental Analysis of Behavior, 11, 1-8.

Delius, J. D., Ameling, M., Lea, S. E. G., \& Staddon, J. E. R. (1995). Reinforcement concordance induces and maintains stimulus associations in pigeons. Psychological Record, 45, 283-297.

Delius, J. D., Jitsumori, M., \& Siemann, M. (2000). Stimulus equivalencies through discrimination reversals. In C. Heyes \& L. Huber (Eds.), Evolution of cognition (pp. 103-122). Cambridge, MA: MIT Press.

FERSEN, L. von, \& Delius, J. D. (2000). Acquired equivalences between auditory stimuli in dolphins (Tursiops truncatus). Animal Cognition, 3, 79-83.

Fields, L., Reeve, K. F., Matneja, P., Varelas, A., Belanich, J., Fitzer, A., \& Shamoun, K. (2002). The formation of a generalized categorization repertoire: Effect of training with multiple domains, samples, and comparisons. Journal of the Experimental Analysis of Behavior, 78, 291-313.

Herrnstein, R. J. (1984). Objects, categories, and discriminative stimuli. In H. L. Roitblat, T. G. Bever, \& H. S. Terrace (Eds.), Animal cognition (pp. 232-262). Hillsdale, NJ: Erlbaum.

HerrnsteIn, R. J. (1990). Levels of stimulus control: A functional approach. Cognition, 37, 133-166.

Herrnstein, R. J., \& DE Villiers, P. A. (1980). Fish as a natural category for people and pigeons. In G. H. Bower (Ed.), The psychology of learning and motivation: Advances in research and theory (Vol. 14, pp. 60-97). New York: Academic Press.

Huber, L., Troje, N. F., Loidolt, M., Aust, U., \& Grass, D. (2000). Natural categorization through multiple feature learning in pigeons. Quarterly Journal of Experimental Psychology, 53B, 341-357.

JiTSUMORI, M. (2006). Categorization of artificial stimuli structured by family resemblance and a prototype effect in pigeons. Manuscript in preparation.

JitsumoRI, M., \& Delius, J. D. (2001). Object recognition and object categorization in animals. In T. Matsuzawa (Ed.), Primate origins of human cognition and behavior (pp. 269-293). Berlin: Springer.

Jitsumori, M., \& MaKino, H. (2004). Recognition of static and dynamic images of depth-rotated human faces by pigeons. Learning \& Behavior, 32, 145-156. 
Jitsumori, M., Siemann, M., Lehr, M., \& Delius, J. D. (2002). A new approach to the formation of equivalence classes in pigeons. Journal of the Experimental Analysis of Behavior, 78, 397-408.

Kendler, H. H., \& Kendler, T. S. (1968). Mediation and conceptual behavior. In K. W. Spence \& J. T. Spence (Eds.), The psychology of learning and motivation (Vol. 2, pp. 197-244). New York: Academic Press.

LEA, S. E. G. (1984). In what sense do pigeons learn concepts? In H. L. Roitblat, T. G. Bever, \& H. S. Terrace (Eds.), Animal cognition (pp. 263-277). Hillsdale, NJ: Erlbaum.

MAKINO, H., \& JiTsumori, M. (2000). [Category learning and prototype effect in pigeons: A study by using morphed images of human faces] Japanese Journal of Psychology, 71, 477-485. [In Japanese with English abstract]

Neiman, E., \& Zentall, T. R. (2000). Common coding of samples associated with the same comparison: The nature of the common representation. Learning \& Motivation, 32, 367-382.

Roberts, W. A. (1996). Stimulus generalization and hierarchical structure in categorization by animals. In T. R. Zentall \& P. M. Smeets (Eds.), Stimulus class formation in humans and animals (pp. 35-54) Amsterdam: Elsevier.

Rosch, E. (1978). Principles of categorization. In E. Rosch \& B. B. Lloyd (Eds.), Cognition and categorization (pp. 27-48). Hillsdale, NJ: Erlbaum.

Rosch, E., \& Mervis, C. B. (1975). Family resemblances: Studies in the internal structure of categories. Cognitive Psychology, 7, 573-605.

Sidman, M. (1994). Equivalence relations and behavior: A research story. Boston: Authors Cooperative.

Sidman, M., \& Tailby, W. (1982). Conditional discrimination vs. matching to sample: An expansion of the testing paradigm. Journal of the Experimental Analysis of Behavior, 37, 5-22.

Sidman, M., Wynne, C. K., Maguire, R. W., \& Barnes, T. (1989). Functional classes and equivalence relations. Journal of the Experimental Analysis of Behavior, 52, 261-274.

Siemann, M., \& Delius, J. D. (1998). Induction of stimulus associations by reinforcement concordances in pigeons. In N. Elsner \& R. Wehner (Eds.), Göttingen neurobiology report 1998 (p. 447). Stuttgart: Thieme.
Troje, N. F., Huber, L., Loidolt, M., Aust, U., \& Fieder, M. (1999) Categorical learning in pigeons: The role of texture and shape in complex static stimuli. Vision Research, 39, 353-366.

URCUIOLI, P. J. (1996). Acquired equivalences and mediated generalization in pigeon's matching-to-sample. In T. R. Zentall \& P. M. Smeets (Eds.), Stimulus class formation in humans and animals (pp. 55-70). Amsterdam: Elsevier.

VAUGHAN, W. (1988). Formation of equivalence sets in pigeons. Journal of Experimental Psychology: Animal Behavior Processes, 14, 36-42.

Wasserman, E. A., De Volder, C. L., \& Coppage, D. J. (1992). Non-similarity-based conceptualization in pigeons via secondary or mediated generalization. Psychological Science, 3, 374-378.

Wasserman, E. A., Kiedinger, R. E., \& Bhatt, R. S. (1988). Conceptual behavior in pigeons: Categories, subcategories, and pseudocategories. Journal of Experimental Psychology: Animal Behavior Processes, 14, 235-246.

Watanabe, S., Lea, S. E. G., \& DitTrich, W. H. (1993). What can we learn from experiments on pigeon concept discrimination? In H. P. Zeigler \& H.-J. Bischof (Eds.), Vision, brain, and behavior in birds (pp. 351-376). Cambridge, MA: MIT Press.

Wittgenstein, L. (1953). Philosophical investigations. New York: Macmillan.

Xia, L., Delius, J. D., \& Siemann, M. (1996). A multistimulus, portable, and programmable conditioning panel for pigeons. Behavior Research Methods, Instruments, \& Computers, 28, 49-54.

ZENTALL, T. R. (1996). An analysis of stimulus class formation in animals. In T. R. Zentall \& P. M. Smeets (Eds.), Stimulus class formation in humans and animals (pp. 15-54). Amsterdam: Elsevier.

Zentall, T. R. (1998). Symbolic representation in animals: Emergent stimulus relations in conditional discrimination learning. Animal Learning \& Behavior, 26, 363-377.

Zentall, T. R., Galizio, M., \& CRitchfield, T. S. (2002). Categorization, concept learning, and behavior analysis: An introduction. Journal of the Experimental Analysis of Behavior, 78, 237-248.

(Manuscript received April 28, 2005; revision accepted for publication September 12, 2005.) 